\title{
"Starring” Madhuri as Durga: The Madhuri Dixit Temple and Performative Fan-Bhakti of Pappu Sardar
}

\section{Shalini Kakar}

"I have been worshipping Madhuri for the last several years. Everyday I do arati for images of my goddess. For me Madhuri is like Ma Durga, and I am her bhakta [devotee].",

Even in March 2008, the sweltering heat of Tatanagar was overwhelming. This was my second visit to the city after being here three years ago in 2005. My objective was to visit the Madhuri Dixit Temple dedicated to Bollywood film star, Madhuri Dixit, and to follow up on the second round of interviews with its owner cum "priest," Pappu Sardar. As I stepped out of the cab, a beaming Pappu Sardar greeted me. I was still exchanging pleasantries, when out of nowhere a group of journalists armed with cameras started clicking my photographs with him. Seeing the bewilderment on my face, Pappu Sardar calmly said, "There are five news channels and ten newspaper journalists waiting to interview you." Considering my humble academic background, I could not understand any reason why the press would be interested in interviewing me: except for the fact that I was conducting research on Pappu Sardar's temple. In three years, his celebrity status and the Madhuri Dixit Temple have acquired national proportion. As I politely refused the news channels, an enthusiastic reporter from the Telegraph came and sat next to me and said, "It's strange that you come all the way from US to do research on Pappu Sardar! To be frank, he is weird and does weird things in the name of Madhuri. In fact, he is only popular among the masses, the elite of the city think he is crazy."

The next day's Telegraph flashed the story, "Madhuri Mania Inspires US Researcher." As I read the article, I was taken aback to find out how I had been (mis)quoted for speaking about Pappu Sardar's activities as "absurd" and about his "persisting eccentricities." I remembered the uneasiness of the journalist and her description of Pappu Sardar as "weird," and yet by publishing the story, she was aiding his popularity. The media has played a significant role in sensationalizing Pappu Sardar's public worshiping of a Bollywood star as a Hindu goddess. ${ }^{3}$ The Madhuri Dixit Temple is actually an eatery or a chaat-shop ${ }^{4}$ owned by Pappu Sardar, which also functions as a space to conduct his devotional activities for his cinematic

International Journal of Hindu Studies 13, 3: 391-416

(C) The Author(s) 2010. This article is published with open access at Springerlink.com DOI 10.1007/s11407-010-9079-y 
goddess. Numerous large posters adorn the walls of Madhuri Dixit Temple, juxtaposed against images of Durga and Guru Nanak. In fact, the media has been instrumental in labeling his shop as a temple. For example, in 2007, while showing a live telecast of the worship of images of Madhuri by Pappu Sardar, Star News refers to his shop as the Madhuri mandir (Madhuri Temple). ${ }^{5}$ In addition, the striking display of huge posters of Madhuri in the Madhuri Dixit Temple also alludes to exhibition practices of a museum. So, how does one reconcile the "absurdity" of Madhuri Dixit Temple that works as a snack shop and a temple, with a display of images of a film star, "sanctified" through the "eccentric" devotional activities of Pappu Sardar? The Madhuri Dixit Temple foregrounds two issues: first, the framework that allows Pappu Sardar's shop to function as a temple, and second, the cultural logic that promotes it, which furthers the agenda of the media and that of Pappu Sardar himself. In this paper, I would like to address the following questions: What makes the Madhuri Dixit Temple an exceptional temple? What kind of a formal and conceptual re-orientation does it take to transform, and for us to understand, a shop that turns into a space of "devotional" exhibitionism embedded in popular Hindu ritual practices projected on the images of a Bollywood star? In other words, how does the Madhuri Dixit Temple become a site for the re-imagination of the Hindu temple that juxtaposes and overlays the diverse spaces of a shop, a temple, and museum-like exhibition and what are some of its cultural and political consequences?

To explore these questions, I will present my argument in three parts. The first part will address how the Hindu temple is being re-conceptualized in post-colonial modernity and how Madhuri Dixit Temple is borrowing from already existing practices of re-appropriation of Hindu rituals in popular culture. In this section, among other examples, I will focus on one such temple, the Bharat Mata Temple in Haridwar dedicated to Bharat Mata (or Mother India). The Bharat Mata Temple reconfigures not only Hindu ritual practices for a nationalist deity, but the structure and display of images in it resonates with that of a museum. The analytical category of a museumtemple in which the function and ideology of both the museum and the temple interpenetrate to produce new spaces and meanings, will allow us to understand how the Hindu temple is being re-contextualized both in its physical and conceptual space in the Bharat Mata Temple. In the second part, applying the same model of a museumtemple to the Madhuri Dixit Temple, I plan to draw a parallel between the Madhuri Dixit Temple and the Bharat Mata Temple suggesting that the premeditated display strategies in the Madhuri Dixit Temple function as a museum exhibit, in which images of Durga and Madhuri occupy the "ritualized" space of this temple. However, since the Madhuri Dixit Temple functions on multiple levels, eventually the notion of a museum-temple explains its character only partially. In the third part, I propose to unpack some of the multiple layered modalities of Madhuri Dixit Temple under the rubric of an exhibition-temple, a conceptual device, which allows us to understand Madhuri Dixit Temple as a polysemic site. This new temple space, which concretizes Pappu Sardar's performative fan-bhakti located on the body of the devotee-fan, is pivotal in consolidating his political identity as part of an emergent 
popular culture.

\section{New Imaginations of Hindu temples}

Scholars such as Stella Kramrisch (1976) and George Michell (1977) have defined the Hindu temple as the dwelling place for god on earth in accordance with Hindu religion. Traditional Hindu temples that fit the definition of Kramrisch and Michell still exist in India. However, in response to the demands of modernity and a rising Indian diaspora, a new category is emerging in Hindu temple types, characterized by newer types of rituals, design, and newer forms of location.

Joanne Punzo Waghorne in Diaspora of the Gods (2004), for example, explains the new temple-building boom in urban residential sites in Tamil Nadu. She attributes the present surge of temple building, both in Tamil Nadu and in the diaspora, to a growing middle-class who claim to represent a new polity. She argues that these new urban temples challenge traditional building types in terms of design, ritual and traditional caste dynamics, becoming "the laboratory for an emerging reconfiguration of Hinduism, with social and cultural consequence" (Waghorne 2004: 5-6, 16). The work of Vineeta Sinha (2005) on Muneeshwaran temples helps us understand the making of a "new" Hindu deity and rituals in urban temples of Singapore. Muneeshwaran, a rural guardian deity in Tamil Nadu is reconfigured as a god of urban dwellers "under the rubric of Singaporean Hinduism" (Sinha 2005: 1). Taking recourse to the concept of "popular Hinduism," which can be loosely defined as one that stems "from a rebellion against the cerebral, anti-emotional formalism of the enlightenment," Sinha states that Muneeshwaran worship encompasses "free and liberal use of deities, symbols and ritual practices associated with the 'other' religious traditions" (foremost among these being Taoism) (2005: 249, 256). Some rituals that mark the construction of a "new" god in the diaspora incorporate "western" practices such as the inclusion of celebrating Father's Day and collective cake cutting in the temple (Sinha 2005: 231). Though Sinha mentions the combining of the non-religious practice of cake cutting in Muneeshwaran temples in Singapore as a new form of devotional expression, the "ritual" of cake cutting in Hindu temples, both in India and abroad, is fast becoming part of neo-Hindu worship practices. It has now been extended to the festival of Janmashtami, celebrating the birth of Hindu God Krishna where devotees in the temples sing "Happy Birthday to Krishna" and celebrate the event by cutting a huge cake on the temple premises. ${ }^{6}$ Other forms of cultural practices emanating from mass media and popular culture, especially the impact of television can be seen in some temples which have been reported to house MTV reality shows ${ }^{7}$ as well as functioning as advertising sites for new television series. $^{8}$

Along with newer construction in design, ritual, function, practices and ideology, the murti in the Hindu temple is also undergoing transformation. The temple murtis in a Krishna ISKCON temple in Mumbai are now being dressed by none other than the famous fashion designer, Manish Malhotra, ${ }^{9}$ who is credited for changing the 
"look" of many Bollywood heroines. In fact, the influence of film and popular "divine" posters that in some cases themselves function as deified objects ${ }^{10}$ is also having an impact on the conception of the murti in temples. In the context of Hindu temples in the southern Indian state of Tamil Nadu, Waghorne observes that Tamil film stars-cum-politicians such as MGR and Jayalalitha who embody a populist style of politics, directly affect the design of temples and murtis. The sculptors seem less constrained by traditional norms of murti making and more inspired by films, state politics, and popular art. "Even the dress of these divine ladies seemed to imitate the cinema celebrities on movie posters: the halter top with sarong is a favorite for wiggly starlets," quips the author, though she promptly adds that these borrowings do not make the images less sacred (Waghorne 2004: 162).

Important for the discussion to follow, the idea of a Hindu temple is not necessarily restricted to the monumental building types discussed above. The temple, or the mandir, can be a concrete, imposing, and monumental structure (usually constructed by and for the elite) or can denote a smaller structure or even an open-air space (usually constructed by the middle- and lower-classes) where people congregate to ritualize an image through Hindu worship rites. Roadside Hindu shrines, consisting of a divinized image of a Hindu deity (sculpture or a poster) or a tree that is ritualized by Hindu worship practices (usually Pipal) on the sidewalk or the pavement are common sights. These open-air or modestly structured street temples have become an expression of a public form of Hindu religiosity. Thus the Hindu temple like the Hindu religion is a fluid concept where the notion of a temple can be applied both to architectural and non-architectural ritualized spaces created around the murti.

Several new temples exemplify the reconceptualization of the Hindu temple by reorienting their spatial and conceptual configuration and practices for new deities. One such example is the Bharat Mata Temple in Haridwar (Figure 1), in which a modern political agenda fuses with the conceptual and ritualistic space of a Hindu temple. In this temple, the Hindu goddess Durga is invoked to posit Bharat Mata as a modern form of a Hindu goddess. Built in 1983, the temple's eight story tall structure rises to a height of 180 feet. Each floor is designed according to a particular theme dedicated to freedom fighters, saints, women who embraced sati, Hindu deities, and so on. Although constructed as a Hindu temple, the Bharat Mata Temple has strong elements of a museum in its construction of space, technology of collection, and display strategies.

According to Tapati Guha-Thakurta, the museum as a "knowledge-producing apparatus" emerged in India as a result of colonial encounter (2004: 43). The objective of a museum in colonial India oscillated between the polar opposites of an ajaib ghar (wonder house) based on spectacle and wonder as perceived by the "natives" and as a place of science and western rationality that aimed to transform the "wondrous into the knowing, scientific gaze" (Guha-Thakurta 2004: 81). However, she asserts that the "native gaze" stubbornly resisted the desired transformation. Even after Independence, the museum as a didactic institution failed to make its mark in India, as it was not able to bridge the gap between the scholar and the lay spectator 
(Guha-Thakurta 2004: 47). The disconnect between these two kinds of visual modes elucidated by Guha-Thakurta may be understood as a "polyscopic"11 "interocular field" 12 which relates to the viewing practices of people in the museum to larger religious, cultural, and visual modes of viewing related to Hindu temple practices, processions, festivals, television, films, posters, and other forms of mass media, which populate the spectator's everyday experience. ${ }^{13}$ Creating a multiplicity of visualities, it operates in multiple domains of secular/religious/sexual, and so on.

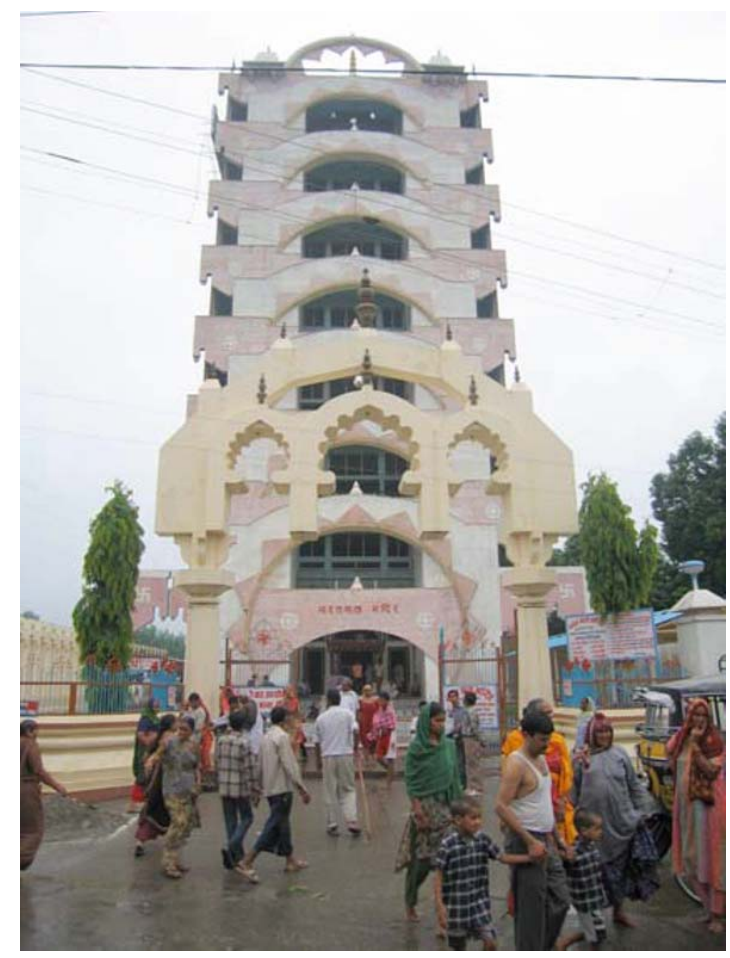

Figure 1. Bharat Mata Temple, 2005. Photograph by Author.

Thus for a museum to be able to bridge the gap between the curators/scholars and the visitors/masses, a new space that "allows" audiences to adapt a polyscopic interocular experience is necessary. This does translate as an expression of religious rituals in museum spaces. However, the similarity between a museum and a temple goes beyond this commonality of rituals into the visual and ideological construction of space in the Bharat Mata Temple.

The Bharat Mata image on the first floor of the temple is displayed behind a glass case with a label titled Vande Bharat Matram, or "Salutation to Mother India," placed at her feet. ${ }^{14}$ An accompanying plaque on the wall behind the image instructs the spectator-citizen about the merits of nationalism. Similar to banners and labels in a museum, these textual references function as "agents of ideological persuasion" 
(Nayar 2006: 134) that induce a particular nationalist reading of the image. Another striking aspect of Bharat Mata Temple is the existence of a map of India in the center of the extended sanctum, which is evidently a visual marker of the temple's political ideology. ${ }^{15}$ Mounted on a raised platform in the center of the first floor, its strategic positioning in front of the murti of Bharat Mata is geared to generate a preferred meaning of the image, echoing with museum display strategies of selection, classification, and presentation of objects to construct and control a particular form of knowledge.

In addition, all other images on various floors, whether posters, sculptures or paintings, are displayed in glass cases with captions and arranged according to particular themes marked at the entrance of each floor, mimicking the idea of thematically organized galleries in a museum. If we think about this example as a museum-temple, certain characteristics suggest the combination of the form of a Hindu temple with that of a museum, in the process fracturing their existing paradigms and redefining them. Such temples display new forms of Hindu deities, who are considered modern avatars of traditional Hindu gods and goddesses framed in the rubric of Hindu religiosity, presented in a museum-like space. The re-appropriation of the Bharat Mata as a Hindu goddess in the Bharat Mata Temple is anchored on one side in the age-old religious and cultural viewing practices of the masses based on temple rituals, and on the other in newer technology-based practices centered around the modernist display strategies of a museum. ${ }^{16}$ The spectator freely engages with the images of the deities (both Bharat Mata and other Hindu divinities) and with paintings, sculptures, and forms of mass media such as photographs, posters, pamphlets, brochures, and books that embellish and circulate in the temple. The spectator-devotee engages in consuming deified images both through the invocation of Hindu rituals and through "modern" viewing practices prompted by glass cases and labels. What is more, Hindu rituals performed inside the Bharat Mata Temple are transfigured into "civic rituals" (Duncan 1995: 2) of the state by being directed to Mother India and the motherland. In this way, the Bharat Mata Temple becomes a ritual site of nationalism, which aims to convert spectators into subject-citizens. This is similar to the goal of museums outlined by GuhaThakurta; here the viewer's polyscopic interocular gaze is negotiated and channeled to serve a particular kind of nationalist discourse anchored in Hindu nationalism. ${ }^{17}$

Another example of a temple that espouses a political ideology framed by Hindu worship practices is the Gandhi mandir in Sambalpur in Orissa. Established in 1974, it is dedicated to Mahatma Gandhi where he is worshiped as a Hindu divinity. Morning and evening prayers are conducted for a bronze statue of the Father of the Nation, placed in the garbha griha (sanctum sanctorum) of the temple that is followed by discourses from his teachings and writings by the priest. ${ }^{18}$ In addition, the proposal of constructing a museum-cum-library in the temple complex along with its emphasis on lectures and health camps ${ }^{19}$ not only echoes with a modernist re-imagination of a traditional Hindu temple, but more specifically as another emerging site of a museum-temple. Similarly, Swaminarayan temples in the West 
with their emphasis on exhibition, profess their own interpretation of religion to become "a devotionally compelling site for the production and sustenance of Swaminarayan-specific desires." 20

However, temples built upon a nexus between Hindu religion and modern politics are not the only ones in which Hindu temples are being re-thought. There are examples of similar worship practices and ritual spaces in which icons not only from the political but also from the cinematic sphere and the arena of sports $^{21}$ are deified, being reconfigured as designer deities. For several years now, the media has been rife with reports of temples dedicated to film stars, both male and female, ${ }^{22}$ especially in South India. ${ }^{23}$ Scholars such as Robert L. Hardgrave (1971, 1993), M. S. S. Pandian (1992), Sara Dickey (1993, 2008), and Preminda Jacob (2009) have written about the superhuman persona of star-politician, M. G. Ramachandran in Tamil Nadu, describing the godly status imparted to him by his fans. Pandian (1992: 130) mentions shrines in MGR's name that were reported to have existed; here the star's idol was ritually installed and worshiped with Hindu modes of rituals by his fans. Besides the adulation of film stars in the south, Bollywood actor, Amitabh Bachchan, has also been deified as a god. Hailed as Kalyug Ka Ram by his fans, there is a shrine for the film star in Kolkata where his fans ritualize his extensively displayed posters, with Hindu worship practices, aligning him with Hindu god Ram. ${ }^{24}$ These temple spaces, focusing on exhibition of ritualized images of stars seem to somewhat resonate with the museum-temple model. At the same time, this model alone cannot contain them: they function as informal sites of star divinization, sans the striking formal architecture or display structure. Instead they tend to become hybrid spaces of a kind of devotional exhibitionism that incorporates various other elements from popular culture. Pappu Sardar's Madhuri Dixit Temple can be seen as the one that builds upon this malleable definition of a temple which leads to the emergence of a new form of the Hindu temple.

\section{The Shop as a Temple}

Similar to the informality of star temples discussed above, Madhuri Dixit Temple is created on the site of a chaat-shop. From the outside one sees a row of shops located in the busy bazaar. The shop displays a big sign called "Manohar Chaat" without any visible sign of a Hindu temple or for that matter a museum. Throughout the year, people primarily come here to eat snacks rather than to pay respects to the cinematic "goddess" or to appreciate the rampant display of Madhuri posters inside the shop.

Since 1996, the chaat-shop has been consecrated as the Madhuri Dixit Temple by devotee-fan Pappu Sardar who holds grand public pujas for the posters of the celluloid goddess (Figures 2 and 3), whom he refers in multiple ways: as his guru, as his elder sister, but primarily as Durga. Since 1996, every year on May 15, Madhuri's birthday, the eatery is converted into a full-fledged temple in which elaborate Hindu rituals are performed. ${ }^{25}$ Hindu priests hired by Pappu Sardar perform yajnas and chant mantras for Hindu God Ganesha, before the puja for "Goddess Madhuri" 
commences. Donning a saffron robe similar to Hindu priests and chanting, "Jai Shree Madhuri Devi Aye Namaha" (Hail to Goddess Madhuri), Pappu Sardar conducts puja for Madhuri's posters. Thereafter, he navigates the streets of Tatanagar in a Madhuri Rath, an open-air truck adorned with deified posters of the star while thousands participate in the "divine" festivities by chanting "Madhuri Dixit ki Jai" (Hail to Madhuri Dixit) with Pappu Sardar. ${ }^{26}$ This is followed by collective "ritual" dancing to the star's popular Bollywood songs, which become Madhuri Bhajans in its present "religious" context. In the end, free chaat, sweets, and birthday cake are distributed as prasad ("consecrated" offering) to everyone. ${ }^{27}$

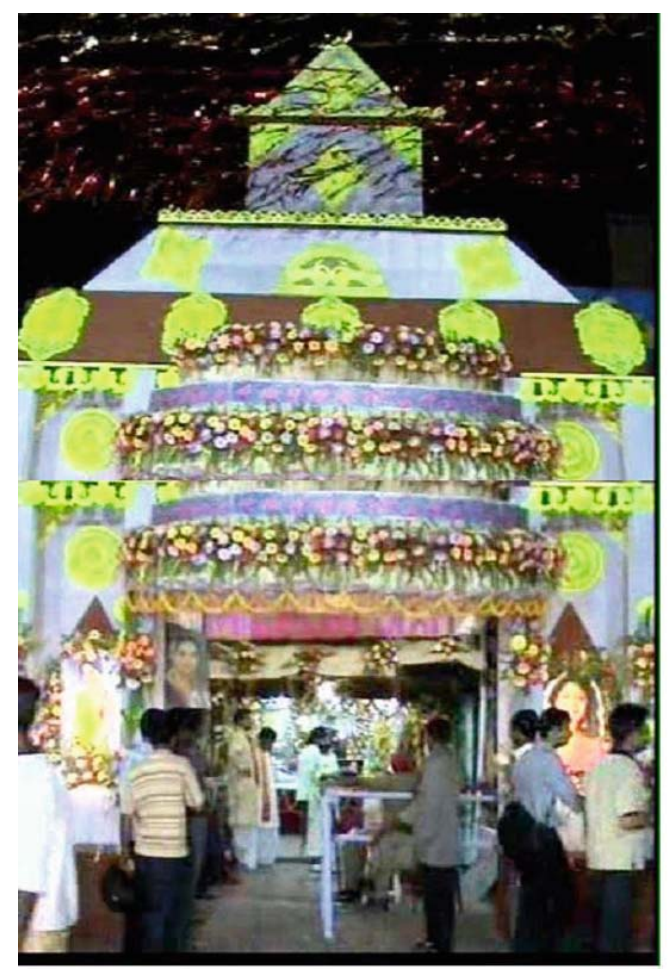

Figure 2. Madhuri Dixit Temple, 2007. Photo Courtesy of Pappu Sardar.

According to Pappu Sardar, 5,000 people gathered to participate in his unique form of devotion in 2008, a number that has been surpassed in the birthday celebrations of May 2009. ${ }^{28}$ In every event at the Madhuri Dixit Temple, Pappu Sardar actively involves the marginalized sections of Tatanagar, such as people from the local old age home, disabled, and eunuchs. For more than a decade now, he has been engaged in social work for the underprivileged, especially in Cheshire Home, a place for physically and mentally challenged women, and the old age home in Tatangar. These otherwise sidelined sections of the society are at the forefront with Pappu Sardar participating in all his major public pujas in which he directly shares media 
space and the limelight with them, especially with eunuchs who engage in frantic "devotional" dancing with him. Inspired by Pappu Sardar's philanthropy, many people who come to be part of the celebrations also make donations for these charity organizations. Madhuri's film releases and Hindu festivals of Holi and Rakhi also propel similar festivities and social mobilization. The involvement of the masses in celebrating the event, particularly the manner in which Pappu Sardar brings in people from the peripheral levels of society into the mainstream, adds another layer of complexity to the collective celebration of his cinematic goddess. Through mass participation in his cinedivine rituals, Pappu Sardar connects his devotional fandom to the collective popular subconscious of the nation created through media images and live telecast of all his celebrations on prominent news channels. Though Pappu Sardar's chaat-shop was constructed by his father solely to serve the purpose of a shop, during Madhuri's birthday celebrations the shop is expanded into an extended pandal, the kind used for religious and social festivities. This notion of the shop as a temple is further reinforced when the visitors who come to pay their respect to the "goddess" on her birthday are allowed inside the Madhuri Dixit Temple only after they remove their shoes outside the premises, entering the "holy" space of the temple barefoot, a practice commonly followed in Hindu temples in India. ${ }^{29}$

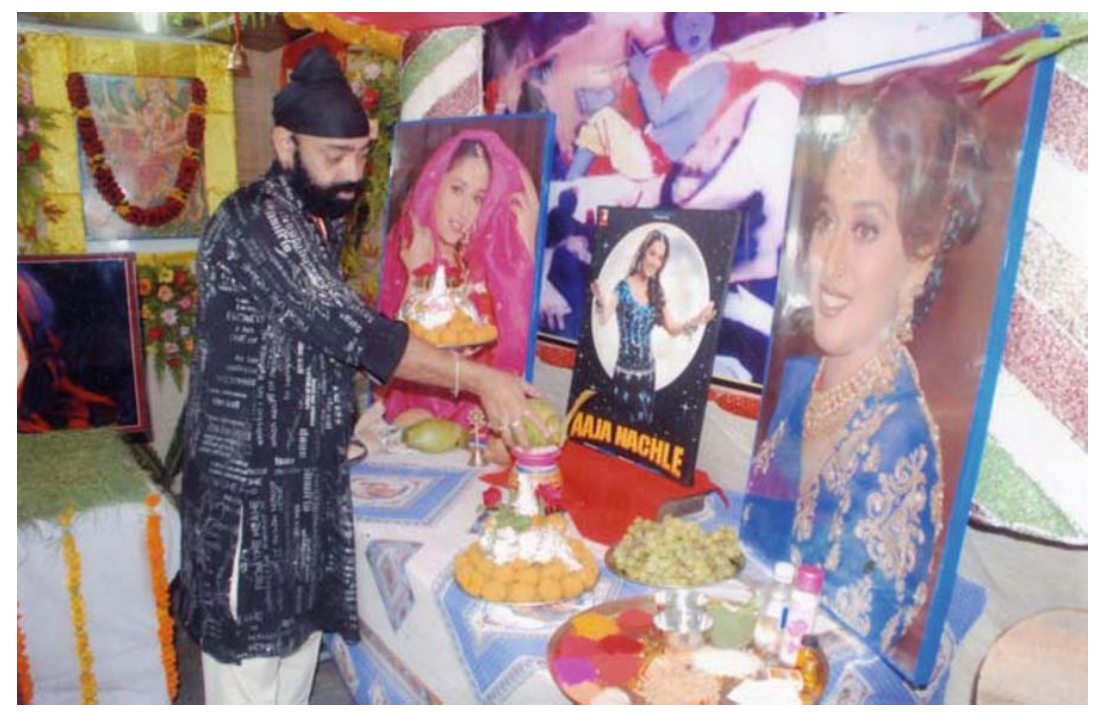

Figure 3. Pappu Sardar Performing Puja of Madhuri Dixit Posters, 2009. Photo Courtesy of Pappu Sardar.

Even in terms of the conception of space and the worship practices of Pappu Sardar, the shop functions as a temple in various ways. Seen in light of Waghorne's work, Pappu Sardar's Madhuri Dixit Temple seems to reflect the idea of an urban temple as it breaks away from traditional norms to assimilate newer deities, albeit by placing a Bollywood heroine at the center of Hindu worship practices. Encouraging 
mass participation from people of different religions, classes and gender, Pappu Sardar breaks away from conventional caste dynamics. His "ritual" of cake cutting and offering it as prasad to the posters of his cinematic goddess while singing "Happy Birthday to Madhuri" in front of the media, stems from a convergence of cultural practices and popular modes of Hindu religiosity that are also being adopted in temples in India and the diaspora. Moreover, his devotional fandom in the Madhuri Dixit Temple can be described as a form of "popular Hinduism" outlined by Sinha, in which Pappu Sardar emphasizes the performative over the cognitive and the cerebral. His hallmark frenzied dancing to the music of Madhuri Bhajans in front of divinized posters of the star, is similar to collective dancing of devotees in front of the murti in Hindu temples, especially during festivals. Likewise, his Madhuri Rath Yatra in Tatanagar has the festive and processional trappings of a regular rath yatra except that it is conducted for a film star. For example, on May 15, 2009, on Madhuri's birthday Pappu Sardar placed a 5 feet, 4 inch replica of the goddess on the Madhuri Rath (Figure 4). At the stroke of midnight on May 14, he perched himself next to the image on the rath. With his trademark dancing, accompanied by eunuchs, cheering crowds and the media in tow, he ceremoniously brought the image to the Madhuri Dixit Temple where he fed it cake as prasad after the cake-cutting ceremony. ${ }^{30}$

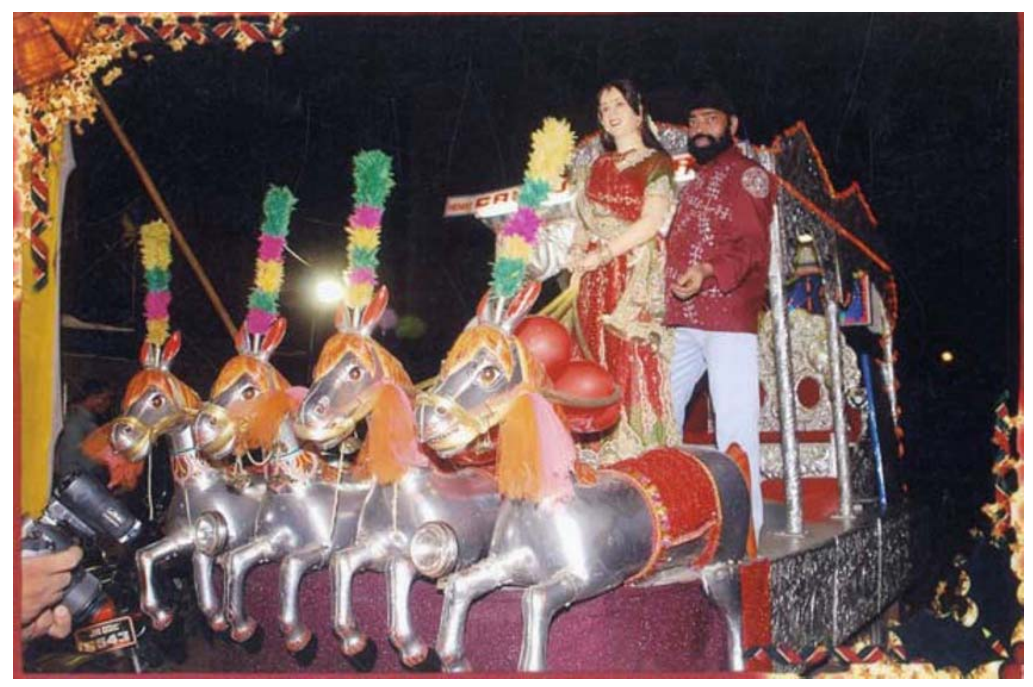

Figure 4. Madhuri Rath, 2009. Photo Courtesy of Pappu Sardar.

Similar to Muneeshwaran temples in Singapore that adopt rituals and deities from different religions, Pappu Sardar also creates a multi-religious space fusing them with contemporary practices. ${ }^{31}$ Although a Sikh, he publicly practices Hindu worship rites for a film star. His Madhuri Dixit Temple houses poster images of Durga, Guru Nanak, Sai Baba, and Muslim pirs within the same "sacred" space of his cinematic 
goddess in his Madhuri Sanctum ${ }^{32}$ (Figure 5). He employs Hindu worship practices to express his devotional fandom as they are part of a larger and dominant mode of cultural expression and work as an effective mode of communication. Moreover, by representing other religions in his temple and adopting an apparently secular outlook, ${ }^{33}$ Pappu Sardar's devotional fandom encompasses a wider field, further adding to its mass appeal.

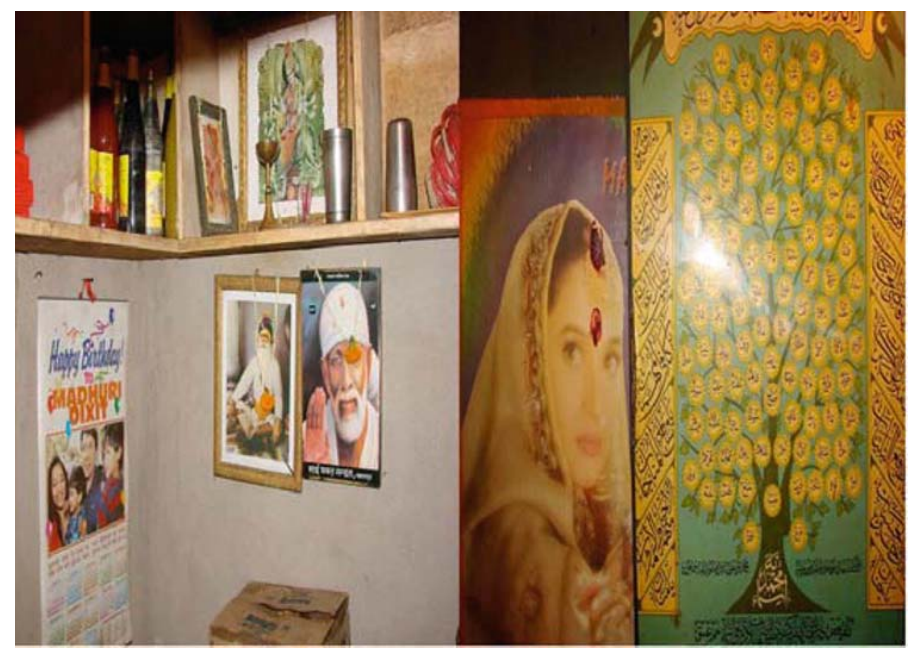

Figure 5. Madhuri Sanctum, 2008. Photograph by Author.

Through the convergence of cinema, religion, and popular culture the Madhuri Dixit Temple becomes another site of re-conceptualization of a Hindu temple where new deities and rituals are being constructed from the world of Indian cinema. Similar to the Bharat Mata Temple, the Madhuri Dixit Temple is not only a space for manifesting a new temple type, but also reflects elements of a museum. A brief investigation into the display of images in Madhuri Dixit Temple will help us understand the ways in which the concept of a museum-temple may be applied to it.

\section{The Museum Ethos and Performative Fan-Bhakti}

Open almost everyday from 10am to 11pm, Pappu Sardar does brisk business of serving chaat and other Indian snacks to his customers. Incidentally, ever since the public display of his devotional fandom and the attention that the media has been bestowing upon Pappu Sardar and his Madhuri Dixit Temple, his sales have increased tremendously. In 2007, in a live telecast of Madhuri birthday celebration, entitled "Madhuri Tera Pappu Deewana" (Madhuri, Pappu is your Admirer), Star News channel anchor while talking to Pappu Sardar commented on his chaat shop, "maine suna hai ki yeh Jamshedpur ki sabse lokpriya chaat ki dukan hai" (I have heard that this is the most popular chaat-shop of Jamshedpur). Though the main 
focus of these programs is to showcase the devotional fandom of Pappu Sardar, in the process the venue of these activities, the chaat-shop, both as a mandir and as a shop, becomes an active point of discussion. Through his devotee-fan activities, Pappu Sardar receives free publicity for his shop on local and national media. In addition, the Madhuri Dixit Temple becomes an advertising site both for small and large businesses that put up their ads and hoardings all along the road of the Madhuri Dixit Temple prior to the birthday celebration of the star every year, in the hope of local and national coverage. The "ethos of the bazaar" (Jain 2003: 41) blends seamlessly with the religious and divinization propaganda of the temple. Though the Madhuri Dixit Temple fuses the role of a shop (commercial) and a temple (religious) as discussed above, yet these two structural and conceptual paradigms do not completely contain the space that is represented through Pappu Sardar's activities.

The collection and striking display of Madhuri posters inside the temple, in some ways resonates with the exhibition space of a museum. The Madhuri Dixit Temple is not a typical museum, as the procurement and display of objects is not its primary purpose. However, in many respects it bears resemblance to museums that depict popular or cultural phenomena. ${ }^{34}$ The interior space, approximately $24 \times 12$ feet in dimension is covered with large posters of Madhuri. Many of the posters have textual references detailing the name of the film and other information, similar to the description of artifacts in a museum (Figure 6). Pappu Sardar changes these posters as in rotating exhibits, though the Madhuri theme persists. The people who visit the chaat-shop may not come specifically to see the displayed images, but the heightened impact of the blown up huge posters encircling the visual space of the customers is inescapable, directing the viewer towards a particular reading of these images rooted in devotional fandom.

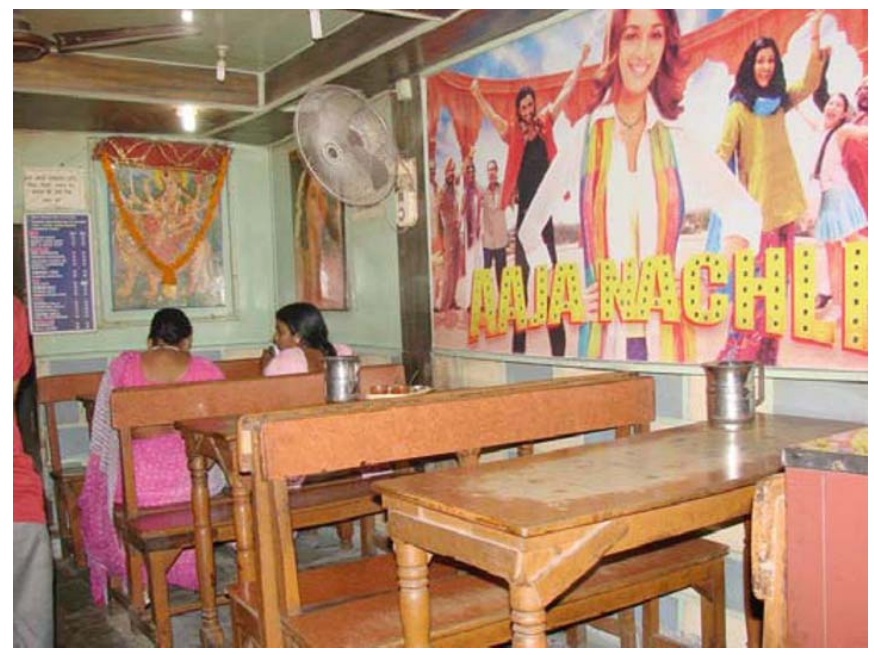

Figure 6. Madhuri Dixit Temple walls displaying huge posters, 2008. Photograph by Author. 
In the Madhuri Dixit Temple, Pappu Sardar not only displays the poster images of Madhuri, but also aligns them with images of Durga and Guru Nanak, creating a particular structure of knowledge through the strategy of visual display. Several museum studies scholars have explored how the "poetics and politics of display" of objects is instrumental in the production of knowledge in the museum. Henrietta Lidchi notes, "Artefacts do not 'spirit' themselves into museum collections: they are collected, interpreted and exhibited - all purposeful and motivated activities" aimed to produce a desired knowledge (1997: 163). Eilean Hooper-Greenhill (1992: 5, 9) questions power relationships that allow certain objects in a museum to be valued more than others and how this system operates to control the parameters of knowledge. She states that the process of selection of images, their presentation, and the sequence of their display in the museum constructs and communicates a particular kind of knowledge that is related to issues of power and control. She points out:

The pedagogic functions of museums can be analysed by reviewing both what is said, and how it is said. Museum pedagogy is structured firstly through the narratives constructed by museum displays and secondly through the methods used to communicate these narratives.... Within museums the phenomenon of display (or of exhibition) is the major form of pedagogy. It is the experience of the display that for most visitors defines the museum, and it is through displays that museums produce and communicate knowledge (Hooper-Greenhill 2000: 3-4; emphasis in the original).

In the Madhuri Dixit Temple, Pappu Sardar arranges the posters of Madhuri, Durga, and Guru Nanak in a sequential manner though the multiple images of the film star visually dominate the space. These posters create the visual space of the spectator inducing them to consume these images not as separate images of a film star, a Hindu goddess, and a Sikh guru, but rather as a cinematic goddess surrounded by her "pantheon," framed by a particular ideological apparatus of the devotional fandom espoused by Pappu Sardar. In addition, he ritualizes Madhuri posters in front of the customers by performing morning and evening arati, echoing with the notion of museum spaces as ritual sites, as proposed by some scholars. ${ }^{35}$ Thus, for the customer/spectator, Pappu Sardar's rituals transform the idea of a poster into a murti, Madhuri as a goddess, and most importantly of Pappu Sardar as her bhakt, or devotee. By looking at deified posters of the film star in the Madhuri Dixit Temple, the spectators also consume the projected meaning behind it: of Madhuri as a form of Durga, which is produced, controlled, and maneuvered by Pappu Sardar. These divinized film posters also find their way into other modes of popular culture through media and cyberspace.

The devotional fandom of Pappu Sardar is not only communicated by the construction of a visual narrative through display of ritualized images in Madhuri Dixit Temple, but also through the "experience of display" which in a museum produces and communicates knowledge. Performance as an element of experiencing the 
display in Madhuri Dixit Temple is pivotal in meaning production. In this case, the experience of the space dominated by ritualized images and the meaning they generate for the spectators is intrinsically connected to the element of performance through which Pappu Sardar animates these images. For example, Pappu Sardar does not visually change the iconography of Durga to fit his new incarnation of the goddess, as in the Bharat Mata murti, but rather frames Madhuri as a goddess by relocating her film poster in a "religious" context, where it shares the same space with the poster of Durga. He conducts arati for Madhuri posters immediately followed by arati for the poster of Durga, thus performatively equating the two in the same "divine" space. In the process he resituates the film poster from a commercial to a sacred domain, transforming it into a star murti. Through constant reiteration of Madhuri as a form of Durga in his interviews and the circulation of the divinized poster among the masses along with his frenzied dances in Madhuri Dixit Temple, on the streets of Tatanagar and on top of the Madhuri Rath, Pappu Sardar mobilizes his ideology of imparting a devotional status to the film star and consolidating his identity of a devotee-fan, thus producing meaning through display and performance. Through performative fan-bhakti, a mode of performance in which Hindu rituals are publicly practiced by devotee-fans of designer deities in recognition of a viewing public, but also in knowledge of the cameras installed by news channels to capture their devotional performance, Pappu Sardar ritualizes posters of his goddess and creates his devotional fanscape.

The performative fan-bhakti of Pappu Sardar in the cityscape and its impact on the masses was also evident in an incident in 2002, when Madhuri's film, Devdas was released. The owner of Uphaar Cinema in Ranchi, a few miles away from Tatanagar, where the film was screened, invited Pappu Sardar to perform puja for Madhuri's film poster inside the theater. Pappu Sardar went in full regalia on his Madhuri Rath, dancing on the streets to the songs of Devdas. According to him, hundreds of people had gathered there to see his dance, so much so that the police had to resort to a lathi charge to disperse the crowd. ${ }^{36}$ In a specially designed outfit for the "show," Pappu Sardar performed Hindu rituals for the Devdas film poster amid much fanfare inside the theater. However, this divinized film poster is different from other such deified images. Printed exclusively for Pappu Sardar by the cinema owners, it not only shows Madhuri's image and has textual references to the cast of the film, but also on the left upper corner of the poster is written, "Madhuri Dixit ke diwane Pappu Sardar ko sneh bhent" (A gift with love to Madhuri's adorer, Pappu Sardar). Similarly, on May 15, 2009 during Madhuri's birthday celebration at Madhuri Dixit Temple, Pappu Sardar decided to ritualize that poster of Madhuri which was gifted to him by the film star herself signed with the following words: "To Brother with Love." Thus the circulation of these kinds of posters in the media (which eventually may get displayed in the Madhuri Dixit Temple or in Madhuri's Puja Room, ${ }^{37}$ that often makes textual references to Pappu Sardar's devotion, directs the viewer towards a preferred reading of the image, beyond that of a film poster. In May 2008, on Madhuri's birthday, Pappu Sardar released a calendar at his shop in front of full 
media glare. This calendar has a photograph of Madhuri with Pappu Sardar taken while he was doing the show for Star News in 2007 (Figure 7). ${ }^{38}$ Other than these images, his bhakti apparatus also includes distributing Madhuri key chains, Madhuri caps, Madhuri pencil boxes, and so on, from his shop on such occasions. In this respect, these divinized posters and fan paraphernalia that circulate both inside and outside Pappu Sardar's shop become the spatial source for the control and dissemination of Pappu Sardar's devotional fandom. The shop becomes a didactic site disseminating the ideology of the devotee-fan to the spectators, thus functioning as a pedagogical "knowledge producing apparatus" as in a museum.

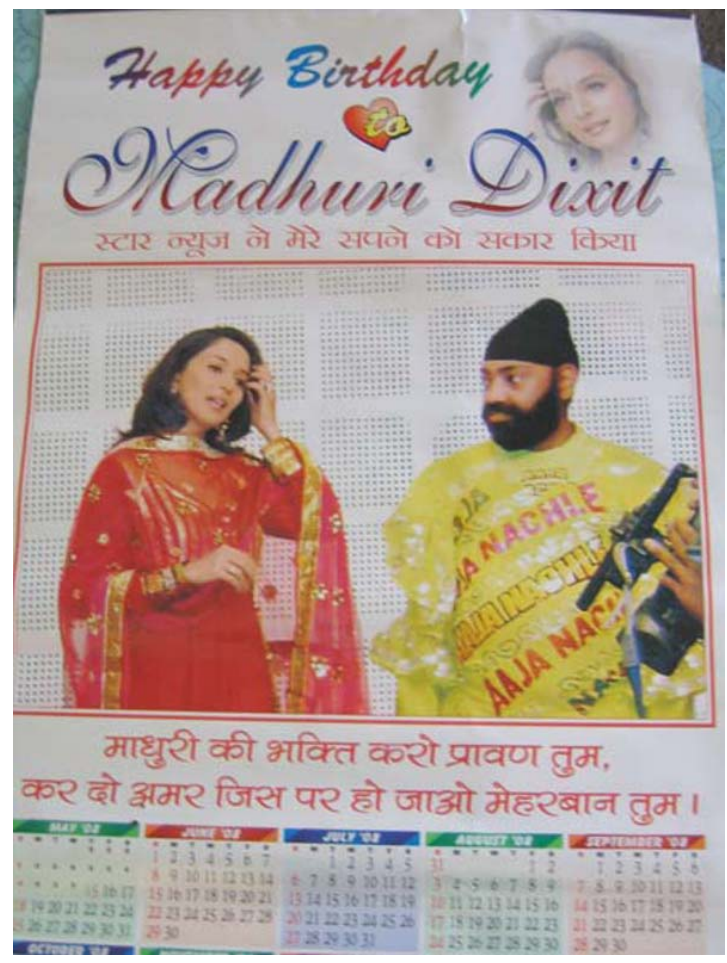

Figure 7. Calendar showing Madhuri with Pappu Sardar. Photo Courtesy of Pappu Sardar.

\section{Exhibition and Popular Politics}

I have argued that both the Bharat Mata Temple and the Madhuri Dixit Temple combine the idea of a museum and a temple. ${ }^{39}$ However, there are some marked differences between the two. For example, the Bharat Mata Temple is enmeshed in a nationalist ideology and as compared to the Madhuri Dixit Temple its structure and appearance is closer to a conventional temple and a museum. Bharat Mata Temple's monumental structure and exclusion from the street readies the spectator-devotee for 
a reverent experience, demanding a particular mode of ritual viewing embedded in religious nationalism. In contrast, Pappu Sardar's Madhuri Dixit Temple works on a populist ideology that cultivates and celebrates the mundane and the everyday and is on the city street rather than away from it. He does not intend to create a museum and is not drawing his display practices from the conventional museum; hence the paradigm of a museum-temple works only partially for the Madhuri Dixit Temple.

The festive informality of display in the Madhuri Dixit Temple reflects the popular mode of exhibition of images, not encased in glass cabinets like museums and away from the burden of "right way of seeing" in monumental buildings. Instead, the visual culture of the Madhuri Dixit Temple is founded on popular practices of display that include the image-centric cultural practices in India such as exhibitioncum-sales, ${ }^{40}$ melas, Durga-pujas, Ganesh-utsavs, Dahi Handi celebrations, where popular religious practices mix with new technology and modern forms of display to produce new forms of cultural production. The people who participate in these events are not guided by museum pamphlets, or tour guides, or taken through controlled walkways surrounding glass cased images. Instead, a free, non-linear, informal approach to crowd movement is encouraged and this "uncontrolled" exhibition space imparts a certain informality of movement, borrowed from practices of street culture. Pappu Sardar's Madhuri Dixit Temple is a juxtaposition of the informality of these festivals with devotional fandom. Rather than aiming to be a site that disciplines the masses, it unleashes them. Instead of a conventional museum, the cinedivine spectacle in the Madhuri Dixit Temple is also more in tandem with the populist, entertaining, playful. and immersive mode of the post-museum.

According to Hooper-Greenhill who coined the term "post-museum," 41 it is a new kind of an institution in which the idea of a museum is reinvented and re-shaped. Whereas the conventional museum is imagined as a building, the post-museum may be imagined as a process or experience, taking varied architectural forms in which the "audiences are able to both consume and produce knowledge" (Hooper-Greenhill 2000: 152-53). Further highlighting the role of the visitors in a post-museum Hooper-Greenhill says:

The production of events and exhibitions as conjoint dynamic processes enables the incorporation into the museum of many voices and many perspectives. Knowledge is no longer unified and monolithic; it becomes fragmented and multi-vocal. There is no necessary unified perspective-rather a cacophony of voices may be heard that present a range of views, experiences and values. The voice of the museum is one among many (2000: 152).

Citing the example of the Experience Music Project in Seattle as a kind of postmuseum that engages audience participation, Chris Bruce suggests that it is "an institution that was born out of the willingness to borrow proven ideas from recreational, entertainment and museum sectors" (2006: 139). He emphasizes the participatory and celebratory mode of the audience in it stating that: 
the environment of...[Experience Music Project] is a spectacle itself-gives visitors a maniac sense of freedom to jump into the fray and participate in a way they might not otherwise. Sing out aloud, bang on the drum: the museum becomes a social place like a festival ground where many different kinds of activities take place simultaneously and where collaboration often occurs (Bruce 2006: 140).

Pappu Sardar creates a similar festive social space in Madhuri Dixit Temple inviting a participatory and collaborative experience, where the audience enthusiastically engages in the celebration of Madhuri Dixit's birthday every year.

However, even though Pappu Sardar actively seeks audience participation, he makes sure that he leads and controls the celebratory activities of the masses by channelizing them towards a pre-planned trajectory of devotional fandom professed by him. While the masses appear unhinged, engaged in uncontrolled frantic dancing and cheering, they undoubtedly end up following the "celebratory agenda" set by Pappu Sardar. For example, before every birthday celebration of Madhuri, Pappu Sardar plans the schedule of events beforehand, deciding the time and style of puja of Madhuri images, cake-cutting, exclusive dancing and singing only on Madhuri bhajans, and for the Madhuri Rath Yatra he decides the route for circumambulating the city of Tatanagar concluding with the distribution of prasad. He informs the media of this plan and sometimes (as in 2007) he gives a running live commentary of his celebration on national television channels so that viewers can watch and visually participate as he embarks on his cinedivine journey with the people of Tatanagar. So, even though the unabashed participatory mode of the masses resonates with the performative and informal exhibition style of popular festivals and the post-museum, the spectacle of devotional fandom generated by Pappu Sardar is geared towards broadcasting his identity of a devotee-fan. The spectacle here does not liberate the audience, empowering them to produce multiple meanings of objects on display as projected in a post-museum. Rather, in this case, it operates as a "selfportrait of power" (Bruce 2006: 129). Thus like the exhibition spaces in a museum, Pappu Sardar directly controls the visual narratives of spectacle and display and the meaning being produced through it, without extending an opportunity to the visitor to be part of the knowledge production at the Madhuri Dixit Temple. For example, the image of Madhuri is primarily framed within the ideological apparatus of a specific Hindu goddess, Durga. The masses are directed towards collective consumption of the image of a "modern cinematic Durga" and her devotee-fan, Pappu Sardar. However, they are not invited to impart another identity either to the star goddess or to her bhakt, even if it entails associating Madhuri with any other Hindu goddess such as Kali, Annaporna, Laxmi, and so on. The deified image of Madhuri remains fixed under the meaning and interpretation provided by Pappu Sardar, which he has been repeatedly reinforcing for more than a decade now. In this way, despite the evident participation of the audience, the performance and exhibition display in Madhuri Dixit Temple becomes a structured and pre-determined didactic process, where Pappu Sardar retains the exclusive "power to create, to make visible, and to 
legitimate meanings and values" (Hooper-Greenhill 2000: 19) assigned to images at Madhuri Dixit Temple, much like in a conventional museum.

Through the public display of his devotional activities and performance, Pappu Sardar is the cynosure of the spectacle of the Madhuri Dixit Temple, which people come to see. The celebration, media hype, and festivities anchored on divinization practices for Madhuri eventually converge on him, rather than on the film star he deifies. The fact that Pappu Sardar refuses to even consider extending his fan club membership to anyone beyond himself, claiming to maintain an exclusive one-man devotee-fan club for his goddess further suggests that he is the center-stage of all the activities in the Madhuri Dixit Temple where the focus shifts from the film star Madhuri to a new celebrity in Tatanagar, Pappu Sardar. Thus the Madhuri Dixit Temple functions as an image-centric, performative, exhibitionary, and propagandistic site that popularizes the devotional fandom of Pappu Sardar and launches the "stardom" of this devotee-fan, empowering him in the process. ${ }^{42}$

Hence, in the Madhuri Dixit Temple, various practices of popular culture comingle to produce an exhibition-temple. An exhibition-temple may be understood as a hybrid polysemic space, which in this case combines aspects of a Hindu temple, museum-like display strategies, the post-museum, practices from popular Hindu festivals (Durga-pujas, for example, or Ganesh-utsavs) and public gatherings/events (such as melas, for example, or exhibition-cum sales) coupled with Pappu Sardar's devotional fandom. As an exhibition-temple, the Madhuri Dixit Temple allows a fluid and performative dimension of devotional fan practices and spectacle centered on and around the display of ritualized star images. This new temple type, which becomes a tangible marker of staging Pappu Sardar's performative fan-bhakti is crucial in circulating his identity of a devotee-fan and in weaving the spectacle of his devotional fanscapes in and beyond this temple, into the city and mediascapes.

With its multifarious complex layering of the cinematic, religious, popular, commercial and technological, the Madhuri Dixit Temple opens up a new social and political space. Pappu Sardar has garnered recognition through his divinization techniques and his social work that has earned him the nickname, "Pappu Bhaiya," who is seen as a local hero in Tatanagar. Even though scorned by the elite, Pappu Sardar has become an emerging social force with a potential to wield political influence in Tatanagar. The power of this devotional fandom is derived from the ability to transform a cinematic image into that of a divine by the devotee-fan. Though the case of Pappu Sardar and his Madhuri Dixit Temple may seem an idiosyncratic and exceptional case of a one-man fan club, it is part of a larger phenomenon of divinization of film stars by organized fan clubs and the emerging star politicians who have a significant political influence in contemporary India.

Walter Benjamin (1992) noted that, by dissipating the aura of art objects, mass reproduction makes possible the involvement of people in cultural production and mass politics. The very nature of mass reproduction contributes to the disintegration of the monolithic character of nationalism (Mitter 2003: 1). But here, Pappu Sardar reinstates the aura in mechanical images by transforming film posters as objects of 
devotion animated by his performative fan-bhakti. This emphasis on performance through the medium of the body of Pappu Sardar, where he himself becomes part of the display, both inside and outside Madhuri Dixit Temple, signals an opening up of an embodied political space. At one level the body as a site of performance becomes a spectacle, but on another carries the potential to operate as a medium of political ideology. In the process, the context of the "political" is changed; it is no longer rooted in the nationalist paradigm based on the textual. In Madhuri Dixit Temple as an exhibition-temple the performative is given precedence over the textual. This represents another logic, stemming not from the "high" culture and the domain of the textual, but rather rooted in the popular religious ${ }^{43}$ and cultural practices of the masses. It represents an emergence of a kind of performative politics, situated on the body of the devotee-fan; the body becomes a site of performative fan-bhakti and in the process, of political ideology.

Performance has been understood as an integral feature of democratic politics that "has enabled the recognition of a significant rupture in political practice, which signifies the coming to power of previously unheard voices in the polity" (Zavos 2007: 151). In other words, performative fan-bhakti of the devotee-fan as a politically loaded space cuts across dominant discourse of power and elite practices, becoming a potential space of political action. By galvanizing the masses with his devotional fandom anchored around the star murti, through the trajectory of the popular and performative fan-bhakti, Pappu Sardar opens up a space of popular politics, located onto his own body. This form of popular politics is forged in a political arena emerging from the grass roots level through devotional fandom and becomes the basis of a new form of political agency founded on the performative.

\section{Acknowledgments}

I owe immense gratitude to my advisor, Professor Swati Chattopadhyay, for her constructive feedback and for going through multiple drafts of this paper. I am also thankful to Professors Barbara Holdrege, Bhaskar Sarkar, John Zavos, and Deepa Reddy for their insightful comments and suggestions.

\section{Notes}

1. Interview with Pappu Sardar, September 2005, Tatanagar.

2. Nilanjana Ghosh Choudhury, "Madhuri Mania Inspires US Researcher," The Telegraph, March 20, 2008. http://www.telegraphindia.com/1080320/jsp/jharkhand/ story_9040070.jsp (accessed December 1, 2008).

3. In 2007, before the release of Madhuri's film, Aaja Nachle, Star News sponsored a meeting between Madhuri and Pappu Sardar and did a special story on his devotion for the film star. As a result of Pappu Sardar's "encounter" with his "goddess," later, Madhuri Dixit sent him a gold rakhi all the way from the US, where she currently lives. This news was reported in a story entitled, "Madhuri ke 
Bhai Sahab" (Madhuri's Brother) in the news channel Aaj Tak, August 2008. http://www.youtube.com/watch?v=b2IYTsibB9c (accessed December 12, 2008).

4. An eating joint that primarily sells chaat, a spicy Indian snack with a tangy taste.

5. “Madhuri, Tera Pappu Deewana," Star News, May 15, 2007.

6. "Cake Cut as Krishna Arrives," The Tribune, September 2, 2002, Chandigarh. http://www.tribuneindia.com/2002/20020902/ldh1.htm (accessed December 9, 2008). "Happy Birthday Krishna: Cake Bhoga Cutting by Swami Gaurangapada on Lord Krishna's 5235's Birthday," http://www.veoh.com/videos/v1207590AaA3qRPY (accessed December 12, 2008).

7. "An MTV film crew shot part of the pilot for their new reality show at the Dallas ISKCON temple this August. The show, which is as yet unnamed, will air in March/April 2009, and features a group of students who explore religions they're unfamiliar with." Madhava Smullen, "MTV Film New Reality Show at ISKCON Dallas," ISKCON News Weekly, August 30, 2008. http://news.iskcon.com/node/ 1255/2008-08-30/mtv_film_new_reality_show_iskcon_dallas (accessed September $15,2008)$.

8. "For the show Jai Sri Krishna, Colors has a tie-up with International Society for Krishna Consciousness (ISKCON), where the show will be promoted at every ISKCON temple in India. Also, Colors has touched 1,000 temples across U.P., Gujarat, and other key Hindi belt states for the promotion of the show, bannering the prasad stalls, giving out Krishna merchandising, literature, calendars." Gaurav Laghate, "ISKCON to Promote 'Jai Sri Krishna' Show on New TV Station," for Doordarshan News, July 26, 2008. http://news.iskcon.com/node/1157/2008-0726/iskcon_promote_jai_sri_krishna_show_new_tv_station (accessed December 12, 2008).

9. Parijata Devi Dasi, "Indian Fashion Icon Designs for Sri Sri Radha Rasabihari," ISKCON News Weekly, 30 August 2008. http://news.iskcon.com/node/1253/200808-30/indian_fashion_icon_designs_sri_sri_radha_rasabihari (accessed December 11, 2008).

10. “'Star-Murtis': Film Posters as Ritual Objects. Hindu Religiosity and Fandom in Popular Culture." Paper presented by the author at the 20th European Conference on Modern South Asian Studies, July 8-11, 2008, Manchester, UK.

11. In context to Indian popular film songs, Taylor brings in two distinct notions of vision specific to South Asia: "One based on the potentialities of drishti, often activated in Hindu religious contexts, and the other based on nazar, operating between imagined worlds of romantic Persianate poetry" (2003: 320). According to Taylor, drishti and nazar, which can sometimes intersect with each other, can also incorporate "western" modes of viewing. Rather than a singular visuality working, Taylor after Martin Jay suggests the polyscopic nature of visual experience.

12. "The gaze of Indian viewers in museums is certainly caught up in what we would call this interocular field.... This interocular field is structured so that each site or setting for the disciplining of the public gaze is to some degree affected by 
viewer's experience of the other sites" (Appadurai and Breckenridge 1992: 52).

13. "What is thus emerging in India, and seems to be a relatively specialized cultural complex, is a world of objects and experiences that ties together visual pleasure, ethnic and national display, and consumer appetite....This constellation, which may be called the 'exhibition complex' (museum-festival-sale), is further energized by new technologies of leisure, information, and movement in contemporary India. Cinema and television (and the landscape of stars that they display), packaged pilgrimages and tours (which takes thousands of ordinary Indians outside their normal locales as part of 'vacation' experiences), and the growing spectacularization of political and sports events (especially through television) all conduce to a new cosmopolitan receptivity to the museum, which would otherwise become a dusty relic of colonial rule. It is these new contexts of public culture that are now transforming the Indian museum experience" (Appadurai and Breckenridge 1992: 40).

14. Clad in a resplendent sari, the figure of Bharat Mata demurely stands holding a sheaf of grains in one hand and a milk urn in another, "signifying the white and green revolution that India needs for progress and prosperity" (Mckean 1996: 156). By changing her iconography from the conventional image of Durga, the goddess is re-appropriated from the realm of Hindu mythology and re-inscribed as a visual icon in the narrative of the modern nation.

15. Although, the Bharat Mata arati and the national anthem performed in the temple premises engage the map in its ritual evocation transforming it into an object of devotion, it functions as a tangible site of the temple's nationalist ideology.

16. It is a classic case of what Chatterjee (2005: 2) states as the tension between mimicry and negation of western ideas of Enlightenment in the newly emerged nation-state of India.

17. The museum-temple also brings in the idea of a museum ingrained in popular culture that engages a larger audience by blending popular modes of Hindu religiosity with mass media. It becomes a site where images and ideology interact in a space that is both accessible and appealing for the "unlearned" gaze of the masses. It becomes India's modern Ajaib Ghar, where the spectator is free or rather "given" a space for a polyscopic visual performance inclusive of modes of popular Hindu religiosity such as reverently bowing in front of images, folding hands, or seeking darshan while viewing images. In this way, museum-temples address the dichotomy faced by museums as described by Guha-Thakurta by bridging the gap between the "gaze of the curator" and the "gaze of the lay spectator."

18. http://www.gandhimandir.com/index.php?option=com_content\&view=article\&id =57\&Itemid=2 (accessed May 8, 2009).

19. http://www.gandhimandir.com/index.php?option=com_content\&view=article\&id =58\&Itemid=54 (accessed May 8, 2009).

20. See Kim's paper in this issue for further reading.

21. "Fans from Indian skipper Mahendra Singh Dhoni's hometown of Ranchi plan to build a temple in his name. 'Cricket is religion in our country and Dhoni is god of 
cricket,' his fan club president Jitendra Singh said. 'We'll construct a huge temple of Dhoni in Ranchi and have a priest who will pray to him every day.' The fan club plans to raise funds through donations and install a 20-foot (six metres) fibre glass statue of Dhoni." "Fans Plan to Build Temple of Dhoni," Indian Express, December 20, 2008. http://www.indianexpress.com/news/fans-plan-to-build-temple-of-dhoni/ 400923/ (accessed June 3, 2009).

22. Temples for Southern film stars such as MGR, Khushboo, Naghma, and more recently Namitha have been reported in several newspapers and magazines. "Khushboo: She's Mother Goddess Now," The Times of India, April 23, 2001. http://timesofindia.indiatimes.com/articleshow/39146293.cms (accessed December 5, 2008).

23. "A temple for popular South Indian actress Namitha is being constructed in Tirunelveli district, $600 \mathrm{~km}$ from here.... 'The initial works are completed. Soon, the stone icon of Namitha will be installed and proper consecration performed,' said S. Selvam, secretary of her fan club....Earlier, a temple was built in honour of Khushboo in Tiruchirappalli district, but it was razed to the ground by irate fans following her controversial comments in 2005 about pre-marital sex to prevent incidence of AIDS." "Southern Siren Namitha has a Temple," July 10, 2008, http://movies.ndtv.com/ newstory.asp?section=Movies\&id=ENTEN20080056519 (accessed June 3, 2009).

24. “' 'Star-Murtis': Film Posters as Ritual Objects. Hindu Religiosity and Fandom in Popular Culture." Paper presented by the author at the 20th European Conference on Modern South Asian Studies, July 8-11, 2008, Manchester, UK.

25. Interview with Pappu Sardar, August 2005.

26. Interview with Pappu Sardar, August 2005.

27. Madhuri Dixit Birthday Celebration CD, May 152007.

28. Phone interview with Pappu Sardar, May 27, 2009.

29. Phone interview with Pappu Sardar, May 27, 2009.

30. The replica is now placed not in the Madhuri Dixit Temple, but in the house of Pappu Sardar.

31. Like the diasporic temples, which have been transforming their design to accommodate both North and South Indian temple style along with co-mingling of deities in order to suit the multiple religious followings of the Indian diaspora, Madhuri Dixit Temple appeals to a larger segment of the society. For example, according to its website the Hindu Temple of Greater Chicago has both North and South Indian deities. "The Rama Temple, which includes Sri Rama, Sita and Lakshmana; Lord Ganesha, Sri Hanuman, Lord Venkateshwara (Balaji), Mahalakshmi, Sri Krishna and Radha." Moreover, the temple functions as an active social site for diasporic Indians. A youth wing (ITW) has been set up to cater to the young generation of Hindus born and brought up in the US. The temple also houses a seniors party group that celebrates Valentine's Day, Mother's Day, and Talent Show, among other events. http://htgc.org/test/index.php?option=com_content\&task=view\&id=29\&Itemid $=43($ accessed December 12, 2008).

32. The Madhuri Sanctum is located at the rear end of Madhuri Dixit Temple. 
Adorned with deified images of Madhuri posters (bearing a vermilion mark) and calendars with that of other divinities, it is an enclosed exclusive space, primarily used by Pappu Sardar for conducting daily worship practices for his goddess.

33. Recently on May 15, 2009 during the celebration of Madhuri's birthday, Pappu Sardar sponsored the wedding of a poor Muslim couple at Cheshire Home, a Christian charity home in Tatanagar. "Though there was some initial reluctance from the couple's family to celebrate the wedding in a Christian Home, I insisted that the marriage will be carried out with full Muslim traditions and I will bear the entire expense of the wedding, except that the date would be on Madhuri's birthday and the venue would not change, as I wanted the inmates to be a part of it. In fact, when the marriage was solemnized, the Sister in charge of the Home personally distributed gifts to the family." Phone interview with Pappu Sardar, May 27, 2009.

34. "With a permanent collection drawing from the most impressive and iconic rock and roll artifacts and a wide-ranging roster of on-going and temporary exhibits, the Rock and Roll Hall of Fame and Museum is dedicated to exploring the past, present and future of the music and the cultural context from which it emerges." http://www.rockhall.com/exhibits/ (accessed December 11, 2008).

35. The performance of rituals for Madhuri posters in a museum-like space of his shop echoes with Duncan's (1995: 2) argument in which she proposes to situate museums and museum practices within the domain of ritual, though not specifically Hindu rituals.

36. Interview with Pappu Sardar, August 2005.

37. Madhuri Puja Room is located in Pappu Sardar's house in Tatanagar. It displays photographs and film posters of Madhuri along with that of Durga, which Pappu Sardar ritualizes everyday through Hindu worship practices.

38. "Fan Goes Beyond B'day Bash," The Telegraph, May 16, 2008. http://www. telegraphindia.com/1080516/jsp/jharkhand/story_9277872.jsp (accessed December 11, 2008).

39. A museum-temple is a place of visual, pedagogical, and material consumption that incorporates designer deities from popular culture, such as the cinematic (Madhuri Dixit Temple) or the political domain (Bharat Mata Temple), or from both. Though museum-temples may sometimes enshrine sculptural form of their deity in glass cases, the temple space is primarily adorned by mass-produced printed images at times accompanied by labels. Unlike the celebration of the aura of "original" artworks in a museum, museum-temples empower the copy. Printed images and sculptures, which become deified in these temples, do not necessarily stand out for their "aesthetic qualities" as they are primarily revered for the divinity "instilled" in them through Hindu rituals. The experience of a "devotee" walking through a museum-temple resonates with that of a spectator going through a gallery of images in a museum. However, the displayed images in this case function as murtis and are meant to evoke a devotional expression from the spectator-devotee. Their positioning and sequencing in the museum-temple space is geared towards constructing a particular ideology and through it to gain control in the production of knowledge via 
images.

40. "The exhibition-cum sale is a major mode of retailing textiles, ready-to wear clothing, books, and home appliances. These merchandising spectacles (which recall the fairs of medieval Europe) are transient, low-overhead, mobile modes for transporting, displaying, and selling a variety of goods" (Appadurai and Breckenridge 1992: 39).

41. A post-museum can be understood as "a utopian display institution that rejects patriarchal authority in order to become a flexible, constantly changing social space prioritizing audience choice, interactivity and pleasure" (Bruce 2006: 129).

42. To read about how fan club members of South Indian star-politician, Chiranjeevi, empower themselves through his star image, refer to S. V. Srinivas's essay, "Devotion and Defiance in Fan Activity" (2000).

43. "Just as the public sphere requires literacy, the publics of bhakti in South Asia require 'embodiment,' the human as medium. This very useful notion of 'embodiment' does not simply exist as a trope of literature, but is deeply engaged in the performance of the discourse of bhakti. By 'discourse' I mean the manifestations of bhakti not only in performance through song or literacy, but also through all those actions and bodily displays that make up bhakti in the broadest sense, such as those outlined above: pilgrimage, puja, darsan, the wearing of signs on the body, and so on. Embodiment, then, is not so much a technique of bhakti as its very epicenter: bhakti needs bodies" (Novetzke 2007: 261).

\section{References Cited}

Appadurai, Arjun and Carol Breckenridge. 1992. "Museums are Good to Think: Heritage on View in India." In Ivan Karp, Christine Mullen Kraemer, and Steven D. Lavine, eds., Museums and Communities: The Politics of Public Culture, 3355. Washington: Smithsonian Institution Press.

Benjamin, Walter. 1992 [1955]. "The Work of Art in the Age of Mechanical Reproduction." In Walter Benjamin, Illuminations: Essays and Reflections (ed. Hannah Arendt; trans. Harry Zohn), 211-44. London: Fontana Press.

Bruce, Chris. 2006 [2005]. "Spectacle and Democracy: Experience Music Project as a Post-Museum." In Janet Marstine, ed., New Museum Theory and Practice: An Introduction, 129-51. Oxford: Blackwell.

Chatterjee, Partha. 2005 [1999]. The Partha Chatterjee Omnibus: Nationalist Thought and the Colonial World; The Nation and Its Fragments; A Possible India. New Delhi: Oxford University Press.

Dickey, Sara. 1993. "The Politics of Adulation: Cinema and the Production of Politicians in South India." The Journal of Asian Studies, 52, 2: 340-72.

Dickey, Sara. 2008. "The Nurturing Hero: Changing Images of MGR.” In Selvaraj Velayutham, ed., Tamil Cinema: The Cultural Politics of India's Other Film Industry, 77-94. London: Routledge.

Duncan, Carol. 1995. Civilizing Rituals. London: Routledge. 
Guha-Thakurta, Tapati. 2004. Monuments, Objects, Histories: Institutions of Art in Colonial and Postcolonial India. New Delhi: Permanent Black.

Hooper-Greenhill, Eilean. 1992. Museums and the Shaping of Knowledge. New York: Routledge.

Hooper-Greenhill, Eilean. 2000. Museums and the Interpretation of Visual Culture. New York: Routledge.

Hardgrave, Robert L. 1971. "The Celluloid God: MGR and the Tamil Film." South Asian Review 4, 4: 307-14.

Hardgrave, Robert L. 1993 [1979]. "When Stars Displace the Gods: The Folk Culture of Cinema in Tamil Nadu." In Robert L. Hardgrave, Essays in the Political Sociology of South India, 92-124. New Delhi: Manohar.

Jacob, Preminda. 2009. Celluloid Deities: The Visual Culture of Cinema and Politics in South India. Lanham: Lexington Books.

Jain, Kajri. 2003. "More than Meets the Eye: The Circulation of Images and the Embodiment of Value." In Sumathi Ramaswamy, ed., Beyond Appearances, Visual Practices and Ideologies in Modern India, 33-70. New Delhi: Sage Publications.

Kramrisch, Stella. 1976 [1946]. The Hindu Temple. 2 volumes. New Delhi: Motilal Banarsidass.

Lidchi, Hendrietta. 1997. "The Poetics and the Politics of Exhibiting Other Cultures." In Stuart Hall, ed., Representation: Cultural Representations and Signifying Practices, 151-222. London: Sage Publications.

McKean, Lise. 1996. Divine Enterprise: Gurus and the Hindu Nationalist Movement. Chicago: University of Chicago Press.

Michell, George. 1977. The Hindu Temple: An Introduction to its Meanings and Forms. New York: Harper \& Row.

Mitter, Partha. 2003. "Mechanical Reproduction and the World of the Colonial Artist." In Sumathi Ramaswamy, ed., Beyond Appearances, Visual Practices and Ideologies in Modern India, 1-32. New Delhi: Sage Publications.

Nayar, Pramod. 2006. Reading Culture: Theory, Praxis, Politics. New Delhi: Sage Publications.

Novetzke, Christian. 2007. "Bhakti and its Public." International Journal of Hindu Studies 11, 3: 255-72.

Sinha, Vineeta. 2005. A New God in the Diaspora?: Muneeswaran Worship in Contemporary Singapore. Singapore: Singapore University Press.

Srinivas, S. V. 2000. "Devotion and Defiance in Fan Activity." In Ravi Vasudevan, ed., Making Meaning in Indian Cinema, 297-317. New Delhi: Oxford University Press.

Taylor, Woodman. 2003. "Penetrating Gazes: The Poetics of Sight and Visual Display in Popular Indian Cinema." In Sumathi Ramaswamy, ed., Beyond Appearances?: Visual Practices and Ideologies in Modern India, 297-322. New Delhi: Sage Publications.

Waghorne, Joanne Punzo. 2004. Diaspora of the Gods: Modern Hindu Temples in 
an Urban Middle-Class World. New York: Oxford University Press.

Zavos, John. 2007. "Understanding Politics through Performance in Colonial and Postcolonial India.” In Timothy Fitzgerald, ed., Religion and Secular: Historical and Colonial Formations, 135-52. London: Equinox.

SHALINI KAKAR is a doctoral student in the History of Art and Architecture Program at the University of California Santa Barbara.<shalini@umail.ucsb.edu>

Open Access This article is distributed under the terms of the Creative Commons Attribution Noncommercial License which permits any noncommercial use, distribution, and reproduction in any medium, provided the original author(s) and source are credited. 